\title{
Dabigatran etexilate: Another Double-Edged Drug?
}

\author{
Editorial to: "The Beneficial Effects of a Direct Thrombin Inhibitor, Dabigatran etexilate, \\ on the Development and Stability of Atherosclerotic Lesions in Apolipoprotein E-deficient \\ Mice" by N. Kadoglou et al.
}

\author{
Juan C. Laguna • Marta Alegret
}

Published online: 18 September 2012

(C) Springer Science+Business Media, LLC 2012

The important limitations and drawbacks of classical parenteral (heparin, low molecular weight heparin and fondaparinux) or oral (vitamin $\mathrm{K}$ antagonists) anticoagulants have prompted the development of novel agents that directly inhibit either thrombin or activated factor X (FXa), two key serine proteases in the coagulation cascade. Currently, two oral anticoagulants (dabigatran etexilate, a direct thrombin inhibitor, and rivaroxaban, an inhibitor of FXa) are approved in more than 70 countries for prevention of venous thromboembolism in patients undergoing elective hip or knee arthroplasty, and in the United States and Europe for prophylaxis of stroke and systemic embolism in patients with non-valvular atrial fibrillation $[1,2]$.

Thrombin and FXa are classically known by their roles in the coagulation cascade, but in addition to their functions in hemostasis in recent years it has been increasingly recognized that they may exert pleiotropic effects in several cell types, acting as signaling molecules through proteaseactivated receptors (PARs). Specifically, thrombin influences diverse physiological and pathological processes, such as inflammation and atherosclerosis $[3,4]$

Atherosclerosis is characterized by the accumulation of lipids, fibrous tissue and cells in the subendothelial space of

\author{
J. C. Laguna $\cdot$ M. Alegret $(\square)$ \\ Pharmacology Unit, School of Pharmacy, University of Barcelona, \\ Diagonal 643, \\ 08028 Barcelona, Spain \\ e-mail: alegret@ub.edu \\ J. C. Laguna $\cdot$ M. Alegret \\ Institute of Biomedicine (IBUB), University of Barcelona, \\ Barcelona, Spain \\ J. C. Laguna $\cdot$ M. Alegret \\ Biomedical Network Research Centre in Physiopathology \\ of Obesity and Nutrition (CIBERobn), \\ Barcelona, Spain
}

large arteries (mainly the coronary, carotid and cerebral arteries). These materials form atheromatous plaques that grow over the years without causing apparent symptomatology until flow-limiting stenosis leads to ischemia, or rupture of the plaque causes thrombus formation [5]. The subsequent clinical manifestations (coronary heart disease and stroke), remain one of the leading causes of disability and death in most industrialized countries and worldwide. Although initially atherosclerosis was considered a mere lipid storage disease, it is now recognized as a phenomenon of inflammatory nature [6-8]. Thrombin is one of the molecules that can contribute to the establishment and propagation of inflammatory processes in atherosclerosis [9]. By exerting pro-inflammatory actions, thrombin may modulate the formation of atherosclerotic lesions in several phases of this complex process. Thus, in initial stages of atherosclerosis thrombin may act as an inductor of endothelial dysfunction $[10,11]$, increasing the permeability of the endothelial barrier $[12,13]$ and inducing the adhesion and transmigration of leukocytes by increasing the expression of leukocyte adhesion molecules such as vascular cell adhesion molecule-1 (VCAM-1), intercellular cell adhesion molecule-1(ICAM-1) and E-selectin [14-16] and chemokines such as monocyte chemoattractant protein-1 (MCP$1)$ in endothelial cells [17]. In more advanced stages, lesions grow by migration of new inflammatory cells, proliferation of smooth muscle cells and extracellular lipid accumulation, and they finally are covered by a fibrous cap consisting of smooth muscle cells and extracellular matrix. At this stage, sustained inflammation inside the plaque is a key factor promoting the growth and destabilization of the lesions. Thus, localized inflammation and the synthesis by macrophages of various proteases that degrade the extracellular matrix (matrix metalloproteinases), contribute to the weakening of the fibrous cap and to plaque instability and rupture. Thrombin also facilitates and exacerbates these later 
phases of the atherosclerotic process: it induces smooth muscle cell proliferation and migration [18, 19], promotes the synthesis of pro-inflammatory and pro-atherogenic mediators inside the lesions [3,9] and acts as a proangiogenic factor [20].

Taking into account the multiple thrombin-related effects that facilitate the initiation, progression, destabilization and rupture of atherosclerotic lesions (Fig. 1), it is logical to propose that thrombin inhibitors could inhibit the atherosclerotic process or at least reduce its progression. In this issue of Cardiovascular Drugs and Therapy, Kadoglou et al. report on the effects of the direct thrombin inhibitor dabigatran, attenuating arterial thrombosis, reducing lesion size and promoting plaque stability in a murine model of atherosclerosis, the $\mathrm{ApoE}^{-/-}$mice [21]. Almost concomitantly, Lee et al. have published an article [22] reporting also an intense reduction in atherosclerotic plaque area using the same animal model and length of treatment, but with a higher dose of dabigatran $(900 \mathrm{mg} / \mathrm{kg} /$ day [22] versus $92 \mathrm{mg} / \mathrm{kg} /$ day [21]). However, one of the most important findings of Kadoglou et al., not reported by Lee et al., is the demonstration that dabigatran not only reduces lesion size, but also increases the stability of the atherosclerotic lesion. Changes in the composition and properties of the plaque that make it more stable and less prone to rupture are more important than the degree of artery stenosis in terms of cardiovascular risk reduction. In this sense, Kadoglou et al. show that dabigatran treatment altered plaque structure and composition, increasing the thickness of fibrous caps, reducing lipid content, increasing the content in elastin and collagen, reducing the number of macrophages and increasing smooth muscle cells [21]. Moreover, the aortic plaque content of matrix metalloproteinase 9 (MMP-9) was reduced, while that of the inhibitor of metalloproteinases TIMP-1 was increased [21], indicating that dabigatran treatment inhibits the degradation of the extracellular matrix, a process involved in plaque rupture.

Although Kadoglou et al. do not go deeply into the molecular mechanisms underlying the above mentioned dabigatran effects, they find a reduction in the aortic plaque content of nuclear factor $\kappa \mathrm{B}(\mathrm{NF} \kappa \mathrm{B})$, which suggests the participation of anti-inflammatory mechanisms due to thrombin reduction. In fact, a former study in $\mathrm{ApoE}^{-/-}$mice treated with another direct thrombin inhibitor (melagatran, now withdrawn from the market) described reduced DNA binding activity of $\mathrm{NFKB}$ and activator protein 1 (AP-1), both transcription factors that control the expression of MMP-9 [23].

In line with the results reported for dabigatran, the direct FXa inhibitor rivaroxaban was also effective in stabilizing advanced atherosclerotic lesions in $\mathrm{ApoE}^{-/-}$mice [24]. Despite the fact that rivaroxaban did not alter the progression of lesions in this model, it increased the thickness of plaque fibrous caps and reduced medial erosions. Again, the stabilizing findings were related to anti-inflammatory mechanisms, as they found a decrease of inflammatory cytokines (interleukin6 , tumor necrosis factor $\alpha$ (TNF $\alpha)$, MCP-1 and Egr-1) in the aortic tissue of rivaroxaban-treated mice [24].

Which are the clinical implications of the three abovementioned studies? At present, despite the advances in the understanding of the complex process of atherogenesis, the main pharmacological approach to reduce atherosclerosis risk is still based on the correction of abnormally high plasma lipid levels, with drugs such as inhibitors of 3hydroxy-3-methyl glutaryl coenzyme A reductase (statins). However, there is a need for other anti-atherosclerotic
Fig. 1 Multiple effects of thrombin on the initiation, progression and destabilization of atherosclerotic plaque. EC: endothelial cells; E-sel: Eselectin; ICAM-1: intercellular cell adhesion molecule-1; IL-1: interleukin-1; IL-6: interleukin6; MCP-1:monocyte chemoattractant protein-1; MMPs: matrix metalloproteinases; SMC: smooth muscle cells; TNF $\alpha$ : tumor necrosis factor $\alpha$; VCAM-1: vascular cell adhesion molecule-1

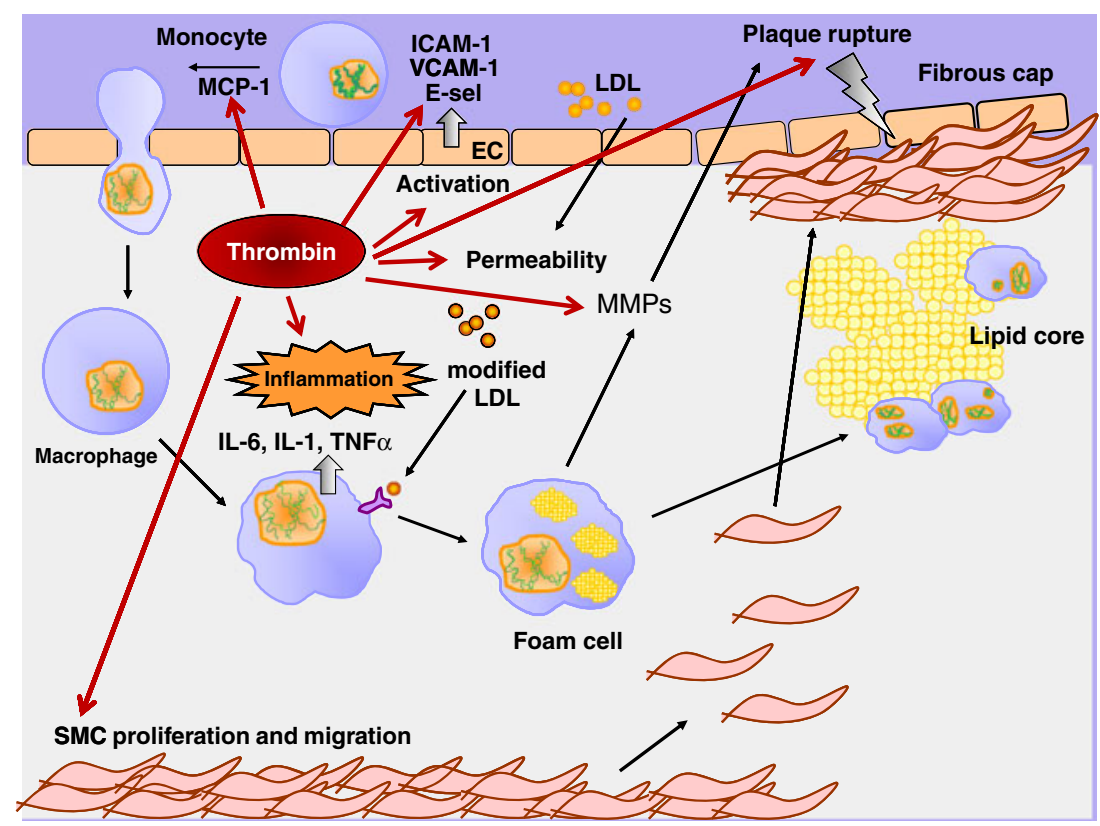


strategies that may act additionally or independently of lipid lowering. From the results presented by Kadoglou, Lee and Zhou [21, 22, 24] one could speculate that thrombin and FXa may constitute novel therapeutic targets to reduce atherosclerosis and its clinical consequences. However, one should not forget that these three studies have been performed in a murine animal model. Several considerations should be taken into account when the results obtained in these mouse models are extrapolated to the human situation. First, the cellular composition of the arterial intima differs between the two species [5, 25]. Secondly, atherosclerotic lesion formation in mice occurs in a matter of weeks, while in humans it takes decades. In mice, the localization and type of lesions that are developed differ from humans [5]. Thirdly, mouse models do not experience spontaneous plaque rupture and subsequent thrombosis, so these animals do not suffer from myocardial infarction (MI) or stroke as a consequence of atherosclerosis $[25,26]$. And finally, the absolute lack of apo $\mathrm{E}$ in the $\mathrm{ApoE}^{-/-}$mice may affect the results obtained in this model, as this apolipoprotein has many different functions in the organism (antiinflammatory, immunomodulatory and antiatherogenic) [27].

In addition, several concerns have recently been raised on safety issues concerning dabigatran and the risk of MI. The larger clinical trial performed up to now with dabigatran (RE-LY study [28]) already showed a significant $38 \%$ increase in MI in patients dosed with $150 \mathrm{mg}$ of dabigatran, compared with those who received warfarin. After data reevaluation, MI incidence in patients receiving dabigatran was reduced to a non-significant $27 \%$ [29]. However, a recent meta-analysis with pooled data from 7 randomized clinical trials shows again that dabigatran is significantly associated with a $33 \%$ higher risk of MI or acute coronary syndromes than that seen with agents used in the control group (warfarin, enoxaparin, or placebo) [30]. A critical lecture of this meta-analysis, however, shows that the reported results are mainly influenced by the results of the RE-LY study, which is by far the largest trial included, and another analysis of the 6 remaining studies shows an odds ratio of only 1.12 , statistically non-significant [31]. In any case, it would be paradoxical that an agent that is able to reduce or at least stabilize atherosclerotic lesions would increase the risk of MI. None of the published reports propose a mechanism for this unexpected effect. One possibility is that dabigatran does not increase the risk of MI, but it is not as effective as warfarin (the drug used in the control arm of the RE-LY study) to prevent the occurrence of acute coronary events [32]. In the future, randomized trials should clarify whether dabigatran or other novel anticoagulant agents are able to modulate atherosclerotic lesions in humans, and also whether these drugs do or do not increase the risk of MI by other unrelated mechanisms.

\section{References}

1. Weitz JI. Factor Xa and thrombin as targets for new oral anticoagulants. Thromb Res. 2011;127 Suppl 2:S5-S12.

2. Eriksson BI, Quinlan DJ, Eikelboom JW. Novel oral factor Xa and thrombin inhibitors in the management of thromboembolism. Annu Rev Med. 2011;62:41-57.

3. Borissoff JI, Spronk HM, Heeneman S, ten Cate H. Is thrombin a key player inthe 'coagulation-atherogenesis' maze? Cardiovasc Res. 2009;82:392-403.

4. Siller-Matula JM, Schwameis M, Blann A, Mannhalter C, Jilma B. Thrombin as amulti-functional enzyme. Focus on in vitro and in vivo effects. Thromb Haemost. 2011;106:1020-33.

5. Libby P, Ridker PM, Hansson GK. Progress and challenges in translating thebiology of atherosclerosis. Nature. 2011;473:31725.

6. Ross R. Atherosclerosis is an inflammatory disease. Am Heart J. 1999;138:S419-20.

7. Libby P, Ridker PM, Maseri A. Inflammation and atherosclerosis. Circulation. 2002;105:1135-43.

8. Libby P. Inflammation in atherosclerosis. Arterioscler Thromb Vasc Biol. 2012;32:2045-51.

9. Croce K, Libby P. Intertwining of thrombosis and inflammation inatherosclerosis. Curr Opin Hematol. 2007;14:55-61.

10. Gudmundsdóttir IJ, Lang NN, Boon NA, Ludlam CA, Webb DJ, Fox KA, et al. Role of the endothelium in the vascular effects of the thrombin receptor(protease-activated receptor type 1) in humans. J Am Coll Cardiol. 2008;51:1749-56.

11. Hirano K. The roles of proteinase-activated receptors in the vascularphysiology and pathophysiology. Arterioscler Thromb Vasc Biol. 2007;27:27-36.

12. Rabiet MJ, Plantier JL, Rival Y, Genoux Y, Lampugnani MG, Dejana E. Thrombin-induced increase in endothelial permeability is associated with changes in cell-to-cell junction organization. Arterioscler Thromb Vasc Biol. 1996;16:488-96.

13. Nobe K, Sone T, Paul RJ, Honda K. Thrombin-induced force development in vascular endothelial cells: contribution to alteration of permeability mediated by calcium-dependent and independent pathways. J Pharmacol Sci. 2005;99:252-63.

14. Minami T, Abid MR, Zhang J, King G, Kodama T, Aird WC. Thrombin stimulation of vascular adhesion molecule-1 in endothelial cells is mediated by protein kinase C (PKC)-delta-NF-kappa B and PKC-zeta-GATA signaling pathways. J Biol Chem. 2003;278:6976-84.

15. Kaplanski G, Marin V, Fabrigoule M, Boulay V, Benoliel AM, Bongrand $\mathrm{P}$, et al. Thrombin-activated human endothelial cells suport monocyte adhesion in vitro following expression of intercellular adhesion molecule-1 (ICAM-1; CD54) and vascular cell adhesion molecule-1 (VCAM-1; CD106). Blood. 1998;92:1259-67.

16. Okada M, Suzuki K, Takada K, Nakashima M, Nakanishi T, Shinohara T. Detection of up-regulated genes in thrombinstimulated human umbilical vein endothelial cells. Thromb Res. 2006;118:715-21.

17. Colotta F, Sciacca FL, Sironi M, Luini W, Rabiet MJ, Mantovani A. Expression of monocyte chemotactic protein-1 by monocytes and endothelial cells exposed to, thrombin. Am J Pathol. 1994;144:975-85.

18. McNamara CA, Sarembock IJ, Bachhuber BG, Stouffer GA, Ragosta M, Barry W, et al. Thrombin and vascular smooth muscle cell proliferation: implications for atherosclerosis and restenosis. Semin Thromb Hemost. 1996;22:139-44.

19. Marutsuka K, Hatakeyama K, Sato Y, Yamashita A, Sumiyoshi A, Asada Y. Protease-activated receptor 2 (PAR2) mediates vascular smooth muscle cell migration induced by tissue factor/factor VIIa complex. Thromb Res. 2002;107:271-6. 
20. Haralabopoulos GC, Grant DS, Kleinman HK, Maragoudakis ME. Thrombin promotes endothelial cell alignment in Matrigel in vitro and angiogenesis in vivo. Am J Physiol. 1997;273:C239-45.

21. Kadoglou NPE, Moustardas P, Katsimpoulas M, Alkistis K, Kostomitsopoulos N, Schafer K, et al. The beneficial effects of a direct thrombin inhibitor, dabigatran etexilate, on the development and stability of atherosclerotic lesions in apolipoprotein Edeficient mice. Cardiovasc Drugs Ther. 2012; this issue.

22. Lee IO, Kratz MT, Schirmer SH, Baumhakel M, Bohm M.The effects of direct thrombin inhibition with dabigatran on plaque formation and endothelial function in Apolipoprotein E-deficient mice. J Pharmacol Exp Ther. 2012 Jul 25. [Epub ahead of print].

23. Bea F, Kreuzer J, Preusch M, Schaab S, Isermann B, Rosenfeld $\mathrm{ME}$, et al. Melagatran reduces advanced atherosclerotic lesion size and may promote plaque stability in apolipoprotein E-deficient mice. Arterioscler Thromb Vasc Biol. 2006;26:2787-92.

24. Zhou Q, Bea F, Preusch M, Wang H, Isermann B, Shahzad K, et al. Evaluation of plaque stability of advanced atherosclerotic lesions in apo E-deficient mice after treatment with the oral factor Xa inhibitor rivaroxaban. Mediators Inflamm. 2011;2011:432080.
25. Bentzon JF, Falk E. Atherosclerotic lesions in mouse and man: is it the same disease? Curr Opin Lipidol. 2010;21:434-40.

26. Badimon L. Atherosclerosis and thrombosis: lessons from animal models. Thromb Haemost. 2001;86:356-65.

27. Zadelaar S, Kleemann R, Verschuren L, de Vries-Van der Weij J, van der Hoorn J, Princen HM, et al. Mouse models for atherosclerosis and pharmaceutical modifiers. Arterioscler Thromb Vasc Biol. 2007;27:1706-21.

28. Connolly SJ, Ezekowitz MD, Yusuf S, Eikelboom J, Oldgren J, Parekh A, et al. Dabigatran versus warfarin in patients with atrialfibrillation. N Engl J Med. 2009;361:1139-51.

29. aTerm Anticoagulation Therapy Investigators. Newly identified events in the RE-LY trial. N Engl J Med. 2010;363:1875-6.

30. Uchino K, Hernandez AV. Dabigatran association with higher risk of acute coronary events: meta-analysis of noninferiority randomized controlled trials. Arch Intern Med. 2012;172:397-402.

31. Correia LC, Lopes AA. Dabigatran and myocardial infarction: meta-illusion? Arch Intern Med. 2012;172:823.

32. Eikelboom JW, Weitz JI. Anticoagulation therapy. Dabigatran and risk ofmyocardial infarction. Nat Rev Cardiol. 2012;9:260-2. 